Available online on 15.06.2020 at http://jddtonline.info
Open Access to Pharmaceutical and Medical Research
(c) 2011-18, publisher and licensee JDDT, This is an Open Access article which permits
unrestricted non-commercial use, provided the original work is properly cited

Open $\odot$ Access

\title{
E-Pharmacy Impacts on Society and Pharma Sector in Economical Pandemic Situation: A Review
}

\author{
Singh $\mathrm{H}^{*}$, Majumdar A, Malviya N \\ Smriti College of Pharmaceutical Education Indore, M.P., India
}

\begin{abstract}
Four month ago, nobody knows about covid-19 but now this virus has spread to almost every country, infecting at least 3,062515 people and death approx 211449 people with badly impact on economies of the most countries and also broken their health-care systems. At this time covid-19 disease is almost spreading all over the world and society. Majorly Pharmacy services act as a pillar at this pandemic situation for the public health. China is the first country where covid-19 outbreak started and some current data of consumer behavior and their habits are showed that society take some safe and preventive measures during lockdown and social distancing time which increase growth of ecommerce demand is inevitable. Now a day's e-pharmacy is being adapted because medications can be ordered in a one click and conveniently delivered to customer door step with some risk like misuse of drugs and self-medication especially for those drugs which comes under the schedule $\mathrm{H}$ and $\mathrm{X}$. This review paper focus on the basic issues and challenges related to online pharmacy and how can it be beneficial to society and pharma sectors in the pandemic situation.
\end{abstract}

Keywords: Online Pharmacy, Internet, Corona virus, Pandemic situation, Pharmaceutical sector.

Article Info: Received 28 March 2020; Review Completed 22 May 2020; Accepted 04 June 2020; Available online 15 June 2020

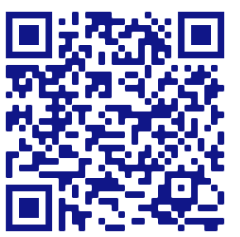

Cite this article as:

Singh H, Majumdar A, Malviya N, E-Pharmacy Impacts on Society and Pharma Sector in Economical Pandemic Situation: A Review, Journal of Drug Delivery and Therapeutics. 2020; 10(3-s):335-340 http://dx.doi.org/10.22270/jddt.v10i3-s.4122

*Address for Correspondence:

Himani Singh, Assistant Professor, Smriti College of Pharmaceutical Education, MR 11, Dewas Naka, Indore 452010, India

\section{INTRODUCTION:}

In the meanwhile from past decades the way to purchase products and services changes and basically internet take over the market and customer buying medications online frequently. Online pharmacy has not only benefits but also have some patient safety risks in purchase of medicines apart from traditional chain ${ }^{1}$. Due to covid-19 lockdown mostly consumers prefer to purchase medicine online. Governments are taking all essential steps for protecting lives by imposing lockdowns, testing, segregation, and treatment. As we all know that infection is spread all over the world so people restricts outdoor movement. For wholesale and retail trade e- commerce is continuously growing day by day. E-commerce companies have witnessed that orders as customers are in online is spike about $20-30 \%$ 2. Globally 2986 online pharmacies were operating in the year 20083. In India 65 Online pharmacy startup were established in 2005 so we have to change the traditional approaches in pharmacy especially the Internet which adds immense value by improving accessibility of healthcare services even to the most remote regions of the country. At the pandemic time for the safety concern consumer buying each everything through online system and also choose home delivery for all essential goods and medicines. So that's why companies are promoting their business through digital technologies and online medicine purchase is popular worldwide due to convenience 4 . In North America and Europe market of the e-pharmacy is approx 29.3 US\$ billion in 2014 as a report said and has been estimated to grow at a CAGR of $17.7 \%$ to reach a valuation of US\$ 128 billion by 2023 (FICCI, 2016). In India e-Pharmacy is at its beginning stage in India with various affects, may be in future it has the potential to be a very large industry segment 5 .

\subsection{E-Pharmacy:}

In past time hand written prescription method for distribution of medicine was favorable but the market of medicine distribution is now being replaced because the boom in the e-commerce so the medicine also distributed online by giving electronic prescription and commonly known as e-pharmacy and also known as, Online, Internet ,Cyber, Tele pharmacy. It is expected that phrama sales in India could be affected by e-pharmacy model approx 5-15\%, if it is held between largely accesses to the medicines for under-served population 6 . It improves convenience and access of consumer. It is importantly benefits those patients who have chronic diseases in a binuclear family and those patients who are not able to go out to find a pharmacy. E- 
pharmacy is a pharmacy that operates over the Internet and sends orders to customers through mail, shipping companies, or online pharmacy web portal. In 2018 the report shows that global e-pharmacy market was approximately USD 42.32 billion and it is expected to generate around USD 107.53 billion by 2025, at a CAGR of around 14.26\% between 2019 and 2025 (Globe news wire 2019)7. Many e-Pharmacy key players are Pharmeasy Medlife, 1MG, Netmeds Myra, CareOnGo and Pharmasafe operates online business. Medlife is leading with about 30\% market share of the total e-pharmacy market in India 8,9.

\subsection{Types of E- Pharmacies}

E pharmacies basically are three types.

1. First one is like traditional drug stores which may be an independent from Internet Company and one operating stores and mail order pharmacies that dispense medicines after receiving prescription.
2. Second one may be clicks-and mortar pharmacy, Major pharmacy has branch chain as actual storefront. In this medication provide by an examination of patient online without physical consultation. This online medication is basically depends upon the questionnaire process evaluated by physician 10 .

3. Ones that dispense medication without a prescription. The first type receives certification from private organization watchdogs and licenses from the states in which they operate. The other two types raise public safety concerns.

Some Pharmacy models are also detailed here. The Inventory-based Model means goods and services sold to customer directly in e-Commerce. The Marketplace-based Model means that it provides information technology platform between a buyer and a seller through Digital network 11. Online business model is shown on Fig 1.

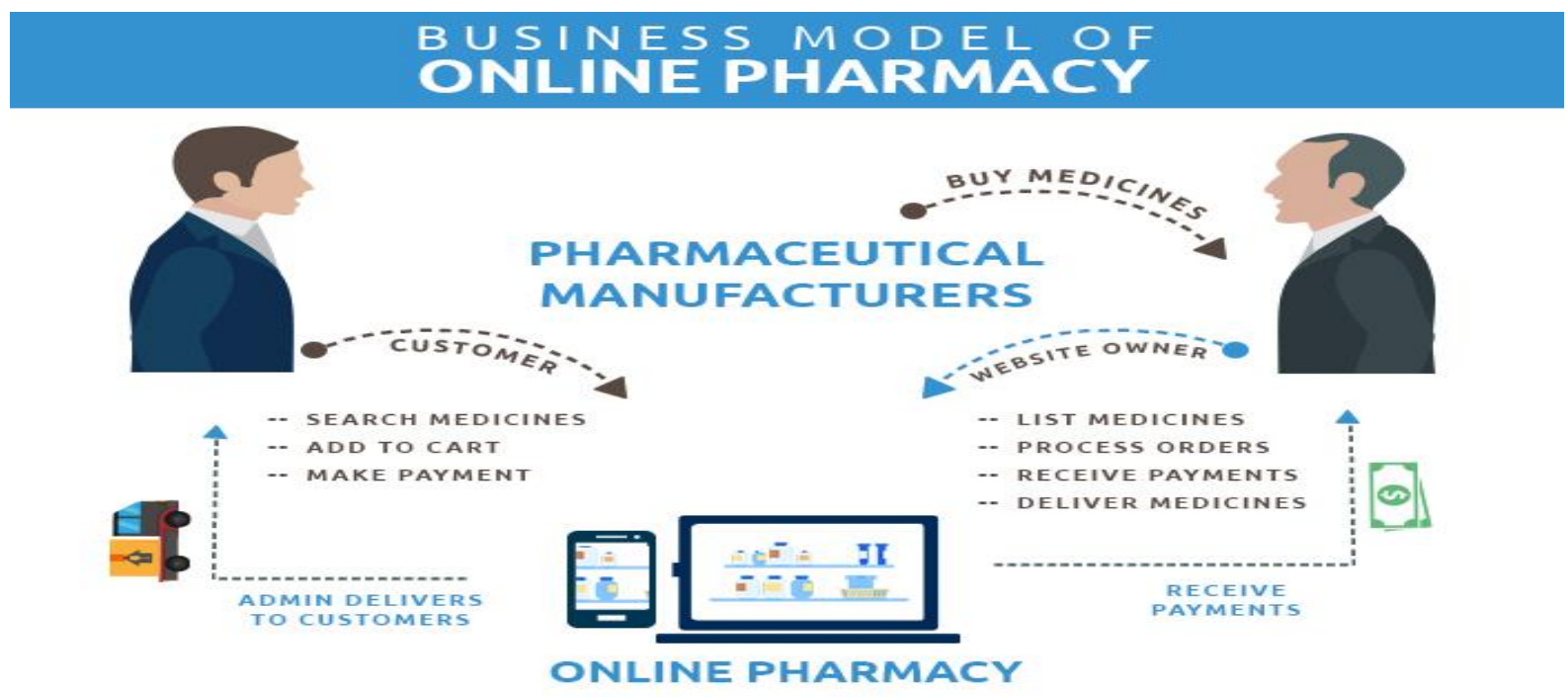

Figure 1: E-Pharmacy Model

\subsection{How does an E -Pharmacy model works?}

1. A scan copy of prescription uploads on the Web or Mobile-based application for medicines request.

2. A team of a registered pharmacist should be checked and verified each and every order.

3. The validated prescriptions send to the pharmacy store by registered pharmacist where medicine can be dispensed

4. All the consumer and pharmacy store activity is govern by IT Act 2000 on the web or mobile based system ${ }^{12}$.

\subsection{Advantages 13:}

1. Money saving

2. Saving Time

3. Consumer convenience is increased

4. Medicines availability is increased

5. Easy accessibility to medicine

6. 24/7 access possible

7. Policy of refund

8. One can easily compare medicines in terms of cost
9. Increased consumer information and information exchange

10. Privacy

11. Delivery of medicines at desired place at desired time possible

12. Fast distribution

13. Increased choice as wider variety of medicines available.

14. Convenient for some patients and old age people who can't leave their home.

\subsection{Disadvantages 14:}

1. Chances of drug resistance and interaction

2. Promote self-medication

3. Chances of drug abuse

4. Financial privacy issues

5. Chances of misdiagnosis

6. Chances of drug misuse

7. Purity and quality of drugs not assured 
8. Electronic health records security and privacy concerns

9. Risks associated with online purchasing of drugs

10. Medical privacy is a major concern

11. Easy availability of illegal substances

12. Sale of drugs without prescription by some epharmacies which lead to harmful consequences

13. Online prescription without consulting a doctor

14. Doctor's prescription may not be honoured

15. Doctor- Pharmacist- Patient: This trio trust evaporates

16. Affect business of offline pharmacists

17. Access to illiterate and poor population difficult

18. Authentication of physicians and pharmacist online is unclear

19. Labelling and packaging related issues

20. Differentiation between legitimate and illegitimate websites for e-pharmacy is tough

21. Temperature sensitive drugs transport is complicated

\subsection{Challenges 15:}

1. For governing e-pharmacies in India a tactile laws in need

2. To sell of drugs to the minors

3. Reach of technology driven model to illiterate people due to lack of knowledge about internet

4. Speed of internet

5. Prescription related issues

6. Legality of electronic signature

7. Identity and reliability of legal e-pharmacy

8. Protection of consumer rights

9. Security and confidentiality of information exchanged

10. Security of financial transactions

11. Regulatory control over e-pharmacies operating outside the jurisdiction of India

12. Unclear laws on inter-state transfer of drugs/medicines.

13. Drug importation and re-importation issue

\section{E-PHARMACY REGULATION IN INDIA}

Regulatory powers in India have been distributed between the central and the state governments. State governments mainly responsible for the manufacturing sale and distribution of medicines while Central Government provide licensing to import of medicines ${ }^{16}$. Two main organization in Central and State Government for the regulatory control over drugs are Central Drugs Control Organization (CDCO) leaded by the Drugs Controller General India and Drugs Control Administration (DCA) leaded by the State Drugs Controllers. States has its own Drugs Control Administration. Law which control over pharmacy regulation are Drug and Cosmetics Act 1940, Drugs and Cosmetic Rules 1945, Pharmacy Act 1948, Indian Medical Act 1956 and Laws related to e-commerce are defined under the Information Technology Act, 2000. Except emergency cases, doctor cannot consult through phone said by Supreme Court. As far as India is concerned, there are no dedicated e-health and telemedicine laws in India. So basically there is no law control over E-pharmacy ${ }^{17}$. We noticed that laws governing the E-pharmacy model as not certain applicability so that key player taking advantage for their business and also found that they are not properly follow the regulation guidelines. There are not clear provisions regarding sale of drugs from internet, it seems very difficult to control, monitor and track sell of drugs through e-pharmacies.

\section{E-PHARMACY DRAFT GUIDELINES:}

Union Health Ministry drafted some rule for the proper regulation of the e-pharmacies on the selling of drug at 28th August 2018. DCGI is a sole agency that should propose the draft guidelines. Two regulatory bodies keep on eye the regulation of the e-commerce of online pharmacies business that is Drugs and Cosmetics Rules 1945 as well as the Information Technology Act 200018. For e-Pharmacies companies are required to take one license in any state and it enable the pharmacies to sell drugs all over the country. If in any circumstances portal failing the follow the guideline under the regulation there should be suspension and cancellation of e-pharmacies so portal should comply all the provision under The Drug and Cosmetic Act, 1940. The drugs should be dispensed under the supervision of registered pharmacist who must verify the details of the patient. The details of the drugs dispensed along with the patient details are to be maintained on the e-Pharmacy portal. Central Licensing Authority is responsible for the registration of the e-pharmacies for running a business with filling a form 18AA along with 50,000 fees and basically it is very important to do a registration for e-Pharmacy portal in selling, distributing, stocking, exhibiting, or offering for sale of drugs. Registration would remain valid for 3 year from effective issue date. Duration of the audit by an authorized team of the CLA is 2 year. After expiration of the registration person should be renew the registration in between 6 month of duration ${ }^{19}$.

Narcotic Drugs and Psychotropic drugs do not come under ePharmacy sale.

Prashant Singh Co-founder, Medlife said "The government as well the CDSCO is very supportive of ePharmacies. There are no regulatory pressures other than expectations of following the laws. The HC judgment too was only with regards to pharmacies selling online who do not carry the valid licenses to dispense and hence operate illegally" 20 .

\section{COMPARISON OF RETAIL OVER E-PHARMACY}

There are various factors that affect both the online and offline pharmacy run. 
Table: 1 Comparison of Retail and E-Pharmacy Aspect 21

\begin{tabular}{|c|c|c|}
\hline S. No. & E-pharmacy & Retail Pharmacy \\
\hline 1 & $\begin{array}{l}\text { One can order medicines anywhere through internet } \\
\text { so it is more convenient form. }\end{array}$ & $\begin{array}{l}\text { Patients go to store for the buying medicines so it is } \\
\text { consider as less convenient form. }\end{array}$ \\
\hline 2 & $\begin{array}{l}\text { Availability of procurement is larger so more } \\
\text { inventory items }\end{array}$ & Less inventory \\
\hline 3 & It saves time because of doorstep delivery & It is time consuming as compared to e-pharmacy. \\
\hline 4 & Range of medicines are more & Range of medicine is less \\
\hline 5 & It provide discount on medicines so offer lower price & $\begin{array}{l}\text { They are not give such offer like online pharmacy due to } \\
\text { less margin }\end{array}$ \\
\hline
\end{tabular}

\section{SOME ONLINE PHARMACY STARTUP}

Table 2: Some of the startup of online pharmacy in India 22.

\begin{tabular}{|c|c|c|c|c|}
\hline S. No & Online Startup & Location & Website & Target \\
\hline 1. & HealthKart 2011 & India & www.healthkart.com & $\begin{array}{l}\text { Online store for health, sport and nutritional } \\
\text { supplements }\end{array}$ \\
\hline 2. & 1mg 2015 & India & www.1mg.com & $\begin{array}{l}\text { Online pharmacy marketplace with doctor } \\
\text { listing and tele consultation services }\end{array}$ \\
\hline 3. & Medlife 2014 & India & www.medlife.com & $\begin{array}{l}\text { Medlife offers an app for purchasing } \\
\text { medicines. }\end{array}$ \\
\hline 4. & PharmEasy 2015 & India & www.pharmeasy.in & $\begin{array}{l}\text { Mobile-first hyperlocal platform for medicine } \\
\text { ordering and diagnostic tests }\end{array}$ \\
\hline 5. & NetMeds 2015 & India & www.netmeds.com & $\begin{array}{l}\text { It offers an online platform selling } \\
\text { prescription, over-the-counter (OTC) drugs } \\
\text { and healthcare and wellness products. }\end{array}$ \\
\hline 6. & EMEDIX 2016 & India & www.emedix.in & $\begin{array}{l}\text { It gives better delivery and excellent services } \\
\text { to the consumers nationwide }\end{array}$ \\
\hline
\end{tabular}

\section{E-PHARMACY IMPACT ON ECONOMY GROWTH}

Telemedicine have adapted at the time of lockdown by governments, hospitals, e-pharmacies and even corporate for their employee wellness 23 .

In 2016 E-Pharmacy market was valued USD 33.03 billion is projected to grow at a CAGR of $14.8 \%$ during the forecast period. Use of internet increased day by day which impact on the improved healthcare infrastructure, rapid aging of the population and e-commerce growth Furthermore, rising adoption of ecommerce and digital technologies in healthcare sector is expected to propel growth 24 . Online pharmacy market in India is in an emerging stage compared to the other developed economies and the major developing economies. In recent years around 250 online pharmacies have sprung up in the country. According to Frost \& Sullivan, the e-pharmacy market in India is estimated to grow at an exponential CAGR of $63 \%$ and reach $\$ 3.6$ billion by 2022 from the current $\$ 512$ million market (2018). E-pharmacy presently accounts for $\sim 1.5-2 \%$ of the total pharma sale according to NetMeds, and $10 \%$ growth estimated for coming 202325.

\section{PHARMACEUTICAL SECTOR IN PANDEMIC SITUATION}

Every industry is impacted by Covid-19 causing head log into the global economy. Pharma industry is also impact by this pandemic situation. The pharmaceutical industry in India is the third largest drug producer by volume and $60 \%$ of vaccines are manufactures in country.
- The cost of the raw material and drug hiked up almost in all over the world due to lockdown for example in India price of paracetamol has gone up to 400-450 Rs per $\mathrm{kg}$ from 250- $300 \mathrm{Rs}$ per $\mathrm{kg}$ and also price of vitamins and penicillin have increased by $40-50 \%$.

- India is major source of APIs for generic drug manufacturing across globe and also supplies approximately $30 \%$ of the generic APIs used in the US. Somehow formulations of drug in India depend upon the China APIs and procure around 70\% from China. According to a recent survey, emergency care, anesthesia care, and pain management drugs are the drugs which mostly get affected due to shortage in the pandemic situation.

- The impact of Covid-19 on demand for drugs availability and the lockdown in various countries so FDA may be force to allow some relaxation policy in review process and regulation on devices.

- Approximately 10 to $15 \%$ earning of pharma firms cur down due to Covid-19 because of disruption of supply chain.

- Digital health platform is booming at the pandemic time.

- The Indian government takes a beneficial step by proposing an incentive package of 13.76 billion Indian Rupees for the promotion of domestic manufacturing of critical key starting materials, drug intermediates, APIs and medical devices. 
- Countries should establish or strengthen pharmacy support services in combating the coronavirus pandemic 26 .

(E-pharmacies are expected to grow 7 times to $\$ 3.7$ billion by 2022 in this pandemic situation which can be a boon for the pharmaceutical industry said by Rajnath Singh) in Pharma times.

\section{E- PHARMACY IMPACT ON SOCIETY}

Some highlighted point when it is beneficial to the society at the pandemic condition

E-pharmacy will be work with other healthcare organizations, professionals, and government agencies to address in that panic situation for customers. As already discussed E-Pharmacies give add value in the health care system because it is more convenient and easily accessible in the pandemic condition when consumers are not go outside due to lockdown and safety concern matter. It is also approachable services due to transparency of price, medicine reminder with health care service provider scheme. Epharmacies slog as "Evolving as a One Stop Solution for All Healthcare Needs".

Medlife spokesperson said, "Our vision has always been to provide as many people with easy access to our end-to-end healthcare offerings from the comfort of their homes. The ongoing Covid-19 pandemic has not altered this vision in anyway, but has pushed us to augment our services, being the largest e-health enterprise in the country. While online medicine delivery service is our main pillar, other services like consultation services and home diagnostics have also seen a spike. With more and more people opting to stay indoors, we are ensuring that they do not forego their necessary diagnostics tests by sending our phlebotomists to their doorsteps."

Some factors why e-pharmacy gains popularity are India ranks high in premature deaths caused by non communicable diseases according to the WHO. Day by day these chronic diseases in India are growing very fast. These non communicable diseases affect by rapid urbanization, mechanization, increased motorization and sedentary lifestyle, especially in adults. Access of medicine in the remote villages is inadequate. The Internet gives knowledge of all the medicines with the help of qualified specialists and doctors, so it difficult for physically locate consumer. Through telemedicine, a village dweller in India can also interact with top specialists anywhere in large cities, or perhaps even globally.

The e-pharmacy websites provide health blogs which provide information about the drugs purchased like indications, adverse effects and dosage requirement. They also provide information and awareness about various medical conditions to increase patient education and awareness.

E-Pharmacy model also give knowledge about the diseases, preventive measure, side effect, herbal treatments and adverse effect and interaction of drug issue related to drug and their treatments just like in the covid-19 information spread globally with the help of internet 27 .

\section{GOVERNMENT INITIATIVE:}

Government of India headed Digital India program perceiving a transformation of country into digitally empowered society with economy knowledge. This program insures that services of Government's are available to citizens by electronically.
Government initiatives in E-health care system. The Ministry of Health \& Family Welfare has undertaken various initiatives using Information \& Communication Technologies (ICT) for improving the efficiency and effectiveness of the public healthcare system. The parts of the e-health care are National health portal, e-Hospital @nic, online registration system and SUGAM 28. These government initiatives will provide online platform for the patient's services and also make people familiar about online health system. Another scheme is Ayushman Bharat Health Insurance Scheme which provides service to create a healthy, capable, and content. Some E-pharmacy startups have tie-ups with health insurers and customers get medicines at cheaper prices which affectively increase the ratio of buying medicines through e-Pharmacy portals. For giving push to the make in India initiative DCGI announced a plan of single-window facility start soon for aiming ease of doing business. Jan Aushadhi Program: This model creates awareness and easily access low price medicine to the population without any compromise in quality. Jan Aushadhi stores provide high quality generic drugs at low prices, create awareness through education and publicity that high prices of drug does not imply high efficacy and potency, Encourage doctors, more specifically in Government hospitals to prescribe generic medicines ${ }^{29}$.

\section{CONCLUSION AND FUTURE PROSPECTIVE}

The objective of the E-pharmacy is development of nation with clear and tangible benefits to the consumers as well as the industry. E-Pharmacy is an attractive model which innovate online healthcare system and also create a huge demand in future. The market size of the e-pharmacy in the next coming 4 year is about 360 million US\$ according to the New EY report. It is more efficient and responsible than local pharmacy in remote areas, which provides easy and affordable medicines to the consumer at their doorstep in a one click and also gives knowledge about the medicinal remedies awareness to the buyer. In a report $76 \%$ respondents said that e-Pharmacy is more convenient as compared to the existing mode of purchase. $35 \%$ of pharmaceutical market in India relates with the chronic diseases and $65 \%$ to acute medicine type so as expected epharmacy can target $85 \%$ of chronic market and $40 \%$ of the acute market in booming the e-commerce business and if it is not properly regulated so it can be dangerous in future. As in the Pandemic situation everything is shut down while most of the brick-and-mortar pharmacies continue to function in lockdown because many consumers have switched to buying medicines online for fear of getting infected by the novel covid-19 and ongoing lockdown has both opportunities and challenges for the e-pharmacy worldwide. As we know that online pharmacy has various advantages and scope increase in e-commerce so that Indian Government must think about the better regulation and can be boon for the society as well as pharmaceutical industry in upcoming years.

\section{CONFLICT OF INTEREST}

Authors have no conflict of interest

\section{REFERENCES:}

1. Fittler A, Vida RG, Káplár M, Botz L, “Consumers Turning to the Internet Pharmacy Market: Cross-Sectional Study on the Frequency and Attitudes Hungarian Patients Purchasing Medications Online" J Med Internet Res, 2018; 20(8):11115.

2. Dadha P. Indian Pharma Set to Target Consumer Online Health Files, 2015. Available at:

http://www.health.economictimes.indiatimes.com/healthfiles/indian-pharma-set-to-target-consumer-online/721.

3. Desai C, "Online pharmacies: A boon or bane?" IJP, 2016; 48(6):615-616. 
4. Ramesh B, Rao CN, Joshi V. Online Medicine Sales: Are you Aware?; Article, 2015. Available at: http://www.pharmabiz.com/PrintArticle.aspx?aid=90368\&si $\mathrm{d}=9$.

5. Chordiya SV, Garge BM, "E-pharmacy vs conventional pharmacy" IJCAAP, 2018; 3(4):121-123.

6. Alamelu R, Amudha R, Cresenta S, Nalini R, “Online Pharma Retail Is A Promising/Unpromising Avenue: An Indian Context" AJPCR, 2016; 9(2): 26-29.

7. Prashanti G, Sravan S, Noorie S, "A Review on Online Pharmacy" IOSR-IPBS, 2017; 12(3):32-34.

8. Nair SP, Middha A, "Ideas and Innovations in Technology" IJAR, 2019; 5(1):1-4.

9. Liu S, Luo P, Tang M, Hu Q, Polidoro JP, Sun S et al. "Providing pharmacy services during the coronavirus pandemic" Int J Clin Pharm, 2020; 42(2): 299-304.

10. Purva S, Ashwini D, "Vigilance for Sale of Drugs through Online Pharmacies" Adv Case Stud, AICS, 2018; 1(3):000511.

11. Mohd A, Mustfa M, "Consumer buying behavior of retail pharmacy industry with special references to Delhi and NCR" IJMSEM, 2017; 2(4):1-17.

12. Jain VH, Tadvi SA, Pawar SP, "A review on the pros and cons of online pharmacies" JAPR, 2017; 5 (1):20 -26.

13. David $M$, "Cybermedicine: the benefits and risks of purchasing drugs over the internet" JTLP, 2000; 5 (2):1.

14. Karnati N, Vishnu P, Kommu V, Sharma Jvc, "Regulations of epharmacy in India” WJPR, 2019;8:421-430.

15. Jain NK. A Text book of Forensic Pharmacy. $7^{\text {th }}$ ed. Delhi: Vallabh Prakashan 2007; 184: 49-54.

16. Priyanka VP, “E-pharmacies regulation in India: Bringining new Dimensions to pharma sector" Pharmaceutical Regulatory Affairs, 2016; 5(2): 15-21.

17. Crawford SY, "Internet pharmacy: issues of access, quality, costs, and regulation" J MED SYST, 2003; 27(1):57-65.

18. Singh R, "Should E-Pharmacy be made Illegal in India?" JMC, 2019; 5(1):18-22.

19. Anatani M, Shukla A. "Online Pharmacies. Indian online pharmacies and drug stores in legal tug-of-war" EHLP, 2015.

20. Thalkari AB, Karwa PN, Gwali CS, "A Review on Online Pharmacy: Views and Counterviews" AJPT, 2018; 8 (2):108111.
21. E-Pharmacy Market by Drug Type (Prescription Drugs and Over The Counter Drugs): Global Industry Perspective, Comprehensive Analysis, and Forecast 2018-2025, Zion market research; Available at: https://www.zionmarketresearch.com/requestbrochure/e -pharmacy-market Accessed June 182019.

22. Top online pharmacies startup: Tracxon Article, 2019. Available at: https://tracxn.com/d/trendingthemes/Startups-in-Online-Pharmacies Accessed 04 December 2019.

23. Alamelu R, Motha CS, Amudha R, Badrinath V, "Pharmaceutical Industry- Studious or spurious? - An Indian Context" RJPBCS, 2015; 6(5): 847-853.

24. Dadhich A, The COVID-19 pandemic and the Indian pharmaceutical industry, Article, 2020. Available at https://www.europeanpharmaceuticalreview.com/article/11 7413/the-covid-19-pandemic-and-the-indian-pharmaceuticalindustry/ Accessed 22 April 2020.

25. Malvern J, Drug runners keep medicines moving during lockdown, Article, 2020. Available at: https://www.thetimes.co.uk/article/drug-runners-keepmedicines-moving-during-lockdown-5khm9lxxj accessed April 2020

26. Chatterjee P, "Indian pharma threatened by COVID-19 shutdowns in China" Lancet, 2020; 395(10225):675.

27. Thacker T. Covid-19 impact: Government panel lists essential drugs that can run out, 2020 Available at:

https://economictimes.indiatimes.com/industry/healthcare/ biotech/pharmaceuticals/covid-19-impact-governmentpanel-lists-essential-drugs-that-can-run out/articleshow/74449944.cms?from=mdr Accessed 03 March 2020.

28. Theodore JC, Matthew SE, "Health Outcomes in Patients Using No-Prescription Online Pharmacies to Purchase Prescription Drugs" J Med Internet Res, 2012; 14(6):174.

29. Mackey TK, Liang BA, "Pharmaceutical digital marketing and governance: illicit actors and challenges to global patient safety and public health" Globalization and Health, 2010; 9:45. 